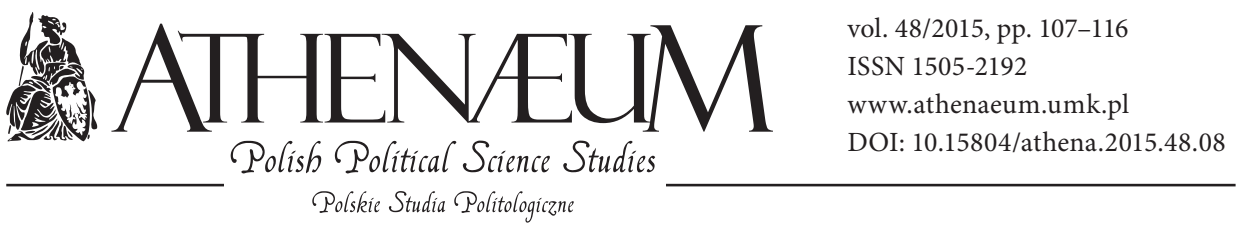

\title{
ROLE OF EMOTIONS AND COMMITMENT IN AN INFLUENCE OF REMEMBRANCE NARRATIVES: REPORT FROM THE EXPERIMENTAL STUDY
}

\author{
Patryk Wawrzyński*, Ralph Schattkowsky**, Marek A. Muszyński***, \\ Gabriela Czarnek****
}

\begin{abstract}
The report presents results of the experimental study on relationships between arousal of emotions and commitment, and an effectiveness of the government's remembrance policy. In measurements, the team manipulated emotions inspired in a narrative (neutral vs. positive vs. negative) and participants' commitment to popularization of a narrative (no commitment vs. low commitment), and it observed how different conditions influenced independent variables: memorization of information, attitude change and real-life behavior. Besides presentation of collected data, the report also includes brief introduction to the theoretical background of the study (especially theoretical hypotheses which verification was project's objective) and a short discussion of final results.
\end{abstract}

\section{- KEYWORDS}

government's remembrance policy, politics of memory, emotions, commitment, experimental political science

* Nicolaus Copernicus University in Toruń, Faculty of Political Science and International Studies.

** Nicolaus Copernicus University in Toruń, Faculty of Political Science and International Studies.

*** Jagiellonian University in Kraków, Institute of Sociology.

**** Jagiellonian University in Kraków, Institute of Sociology. 


\section{THEORETICAL BACKGROUND OF THE STUDY}

The main objective of the experimental study was an observation of relationships between arousal of emotions and commitment, and an influence of remembrance narratives. Moreover, its aims were the initial validation of theoretical hypotheses on the effectiveness of the government's remembrance policy and the development of existing knowledge on the remembrance as a political asset. Realization of the study was possible thanks to the establishment of research team which included investigators specialized in political science, contemporary history, psychometrics and social psychology. Therefore, it may be considered as an innovative attempt to introduce experimental methodology into political science's approach to narrating past experiences.

In the study, we used own general definition of the government's remembrance policy, which we have constructed with reference to relevant features of individual memory (Crawford 2006: 226; Grosswald Curran 2003: 321-322; Hoskins 2007: 246-247; Kattago 2001: 28-30; Koczanowicz 1997: 259-260; Labanyi 2008: 120-121; Maruszewski 2001: 117-118; Smith 2003: 56-59; Uldricks 2009; Westen 2008: 41-49). We recognized it as an act of intentional narrating past events and interpretation of them by a government, which objective is to influence on political identity of a society, social-shared knowledge - beliefs, ideas, and values - or political attitudes and behaviors, thanks to management of collective memory's contents and/or emotional involvement of a recipient. The policy includes two basic strategies - remembering and forgetting of events - which application results from a government's decision concerning which narratives are essential for political identities and may inform a society in the present or in the future (Gillis 1994: 15; Misztal 2010: 26; Singer, Conway 2008: 279-285). Therefore, we understand it as an instrument of social influence and a peculiar type of political communication (Cialdini 2003).

In the arrangement of measurements, we focused on two theoretical hypotheses on the effectiveness of the remembrance policy. Firstly, we recognized that it is emotional, so its possible influence is dependent on the use of emotions in a narrative (Levenson et al. 1990; Schwarz, Clore 1983; Turner 2007: 170). This hypothesis can be developed on three different levels: (1) emotions transforms citizens' attitudes in compliance with a vector of narrative (Landau et al.2009), (2) application of different emotions causes opposing results from citizens' well- 
being and cooperative behaviors to grief, anxiety, or aggression (Fredrickson, Losada 2005; Baumeister et al. 2001), and (3) positive emotions inspire creativity, activate learning processes and reduce stress, while negative emotions cause defensive fight-or-flight response and limit recipient's openness to new ideas (Boyatzis et al. 2013: 160-164; Barsade, Gibson 2009; Boyatzis et al. 2014; Porges 2001). Secondly, we considered the policy as based on commitment, so its effectiveness can increase if popularization of narratives inspires establishment of relationships between recipients and their active participation in story-telling (Kiesler 1971, 1977; Kiesler, Munson 1975; Burke, Stets 2009). Therefore, we assumed that presence of committing acts influence both attitudes and behaviors of recipients and it makes them more prone to persuasion (Schwartz et al. 1980; Rao, Monk 1999), which is an objective of the remembrance policy.

Thus, the realized research project was based on a new approach to the government's role as a narrator of past experiences. Moreover, its goal was not a description of employed strategies or instruments of the policy, but an observation of narrative's influence in controlled, laboratory conditions. Therefore, its results have an explanatory value and they can be used to explain a role of the remembrance as a political asset, but concurrently these observations may be used as suggestions how to realize the policy in practice.

\section{RESEARCH METHODOLOGY}

The experimental study was realized in December 2014 and January 2015 at the Nicolaus Copernicus University in Torun and its Medical School in Bydgoszcz. We recruited 364 male and female participants (age: 18-29, average age: 21 years old) representing different branches of science: social science, life science, physical science, and formal science. The research sample was selected accidentally, because the recruitment procedure was based on voluntary participation in the experiment. Therefore, we do not recognize results as representative for the population, but as an observation realized in conditions which imitated specific character of the government's remembrance policy.

In the study, all 364 participants were randomly assigned to six experimental conditions based on the research design. We used two dependent variables: arousal of emotions (neutral vs. positive vs. negative), and arousal of commitment (no commitment vs. low commitment), and we observed differences in three independent variables: memorization of information, change of attitudes 
towards the remembrance policy, and real-life behavior of participants. We used three short films about the 1945 Augustów Roundup to manipulate arousal of emotions - the first was emotionally neutral, the second had additional inspirations of pride, while the third had additional inspirations of sorrow ${ }^{1}$. We also asked participants to write a short informative text about the presented narrative (no-commitment condition), or to write a short persuasive text which promoted the narrative ${ }^{2}$ (low-commitment condition). Thus, every participant was randomly assigned to watch one of three films and to write one of two short texts related to the topic of presented story.

During the realization of the project, we not only directed (after testing their contents) three short films about the 1945 Augustów Roundup, but we also created two unique research tools. The first was the test of knowledge on Communist Crimes in Poland, which included 11 questions, selected after pretest with 101 participants. The second innovative tool was the attitudes towards the government's remembrance policy questionnaire, that was constructed on the basis of pretest with 449 students from Torun and Kraków. Moreover, we asked ten experts in the fields of political science and history to evaluate question's relevance. As a result, we established two parallel versions of the questionnaire (A and B) with 17 items each, including two reverse questions each. During measurements, participants were asked to express their support for presented statements on the seven-level Likert scale ${ }^{3}$. The tool covered cognitive, behavioral, and emotional sides of attitudes (Böhner, Wänke 2004: 15-18).

All realized experiments had the same scenario. After confirmation of the will to participate in the study, students were asked to share basic information (sex, age, academic major) and to assess their interest in history and politics. Secondly, they completed the first copy of the attitude questionnaire ${ }^{4}$, followed by the Need for Closure questionnaire (Kossowska 2003; Kossowska et al. 2014), and the test of knowledge. Thirdly, a film was showed. Fourthly, participants

${ }^{1}$ Films were realized by Marcin Wziętek (Nowy Warsztat) and they starred Jarosław Felczykowski (Wiliam Horzyca Theatre in Toruń) as a narrator.

219 participants wrote a short persuasive text against the suggested thesis, therefore, we recognize them as a group who experienced reverse low commitment.

${ }^{3}$ In the study, we used the following format: 1 - strongly disagree, 2 - disagree, 3 - rather disagree, 4 - neither agree nor disagree, 5 - rather agree, 6 - agree, 7 - strongly agree. Total minimal score in the measurement: 17 points; total maximal score: 119 points.

${ }^{4}$ Participants were randomly assigned to start with version $\mathrm{A}$ or version $\mathrm{B}$ of the questionnaire. 
were asked to fill out the manipulation check form and to answer four simple questions about presented narrative. Fifthly, they were asked to write a short informative or persuasive text. Finally, participants completed the second copy of the attitude questionnaire. All measurements lasted less than 45 minutes. After seven days, students were informed about a possibility to sign a petition to the President about commemoration of the Roundup, what enabled us to observe their behavior in real-life.

\section{MEMORIZATION OF INFORMATION}

In general, average result in the measurement of memorization was 3,62 points per four possible $(90,50 \%)$. We observed differences between particular questions: a name of the hero's organization (average: 0,93 points), a number of victims (average: 0,80 points), a name of the hero of narrative (average: 0,91 points), and a place of events (average: 0,97 points). Moreover, we noticed that sex, age, interest in history and politics were irrelevant for the result of memorization test, while participants with more developed knowledge on Communist Crimes had higher results in this test. We also observed interesting differences between students with different academic majors: the highest average results had students of pharmacy ( 3,89 points), security studies ( 3,86 points), and cognitive studies (3,83 points), while the lowest average results had students of social work (3,30 points) and biotechnology (3,33 points). Moreover, we noticed that participants who experienced pride or anger stronger, and who found a film more touching, tended to better memorize information.

As we predicted, participants assigned to the emotionally neutral condition had slightly higher average result in the memorization test, and they scored 3,67 points $(91,75 \%)$, while both groups with additional arousal of emotions scored 3,60 points $(90,00 \%)$. More interesting are differences in particular questions - in the case of an organization's name inspiration of emotions caused better memorization (neutral: 0,90 ; pride: 0,95 ; sorrow: 0,95 ), while in the case of a number of victims the neutral version was significantly more successful (neutral: 0,88 ; pride: 0,75 ; sorrow: 0,78 ). The hero's name was slightly better memorized by students who watched film with additional arousal of pride (neutral: 0,91 ; pride: 0,93 ; sorrow: 0,91 ), and in a question on a place of events we did not noticed differences (neutral: 0,98; pride: 0,97; sorrow: 0,97). Moreover, there were no significant dissimilarities between results of groups assigned to start with different ver- 
sions of the questionnaire or assigned to no-commitment or low-commitment condition; however, students who experienced reversed commitment had more problems with answering these four questions (average: 3,16 points), especially the item related to a number of victims (average: 0,63 points).

\section{ATTITUDE CHANGE}

In the first measurement, the average score in the attitude questionnaire was 73,90 points, what suggests moderate support for the remembrance policy, while in the second measurement, the average score was 75,82 points, what shows that presentation of the narrative caused a move to rather positive attitude towards the policy. Therefore, we observed that a support - on average - increased by $\mathbf{2 , 6 0 \%}$. In general, the change was more visible in attitudes of female participants (3,20\%; male: $0,69 \%)$ and it was not correlated with age. In the case of academic majors, we observed more significant change in attitudes of students of pharmacy $(6,32 \%)$, social work $(6,00 \%)$, cognitive studies $(5,52 \%)$, education studies (5,52\%), and management (4,66\%), while it was irrelevant in the case of students of mathematics $(0,30 \%)$ and economy $(0,40 \%)$.

The highest increase was present in groups highly interested in history $(4,96 \%)$ and not interested in it (4,58\%), while a decrease occurred only in a group highly not interested in it $(-2,82 \%)$. In the case of interest in politics, the highest increase was present in groups not interested in it $(5,91 \%)$, rather interested in it $(5,31 \%)$ and highly interested in it $(4,34 \%)$, while a minimal decrease occurred in a group highly not interested in politics $(-0,08 \%)$. Moreover, knowledge on Communist Crimes could not be used to predict attitude change - only participants who scored less than two points per eleven possible showed less support for the policy $(-10,08 \%)$, while the highest increase occurred in group who scored two points $(4,42 \%)$ and in group who scored seven and more points $(3,72 \%)$. These results suggest that the remembrance policy should not focus only on citizens interested in history and politics with more developed knowledge, but also it should target these citizens who do not express their interest in the past and who are less educated in the national history.

In the experimental study, we noticed the highest average increase of support in a group of participants who were assigned to watch a film with additional arousal of pride $(3,54 \%,+2,59$ points), lower increase in a group assigned to the emotionally neutral condition $(3,10 \%,+2,34$ points $)$, and the lowest one in 
a group that watched a film with additional inspirations of sorrow $(1,15 \%,+0,83$ points). Even more noticeable differences were present between participants who experienced low commitment $(3,42 \%,+2,57$ points), lack of commitment $(2,37 \%,+1,75$ points), and reversed low commitment $(-3,19 \%,-2,00$ points). It is clear that observed attitude change was not radical, but we have to emphasize that it was a result of just watching one short film and writing one short text, and discussed changes occurred in only half an hour.

Combination of two dependent variables' influence also lead us to valuable observations. The most favorable - in terms of attitude change - was presence of positive emotions (pride) and a committing act ( $4,60 \%,+3,42$ points), while without arousal of commitment watching this film caused significantly smaller increase $(3,05 \%,+2,22$ points). Even more visible is difference between presence of a committing act in the case of a film with additional inspirations of sorrow (low commitment: $2,49 \%,+1,85$ points; no commitment: $0,66 \%,+0,48$ points). However, in a group assigned to watch an emotionally neutral film, slightly higher increase was observed in no-commitment condition $(3,33 \%,+2,52$ points; low commitment: $3,13 \%,+2,42$ points). Moreover, neutral version reduced impact of reversed low commitment $(-1,30 \%,-0,80$ points; pride: $-1,98 \%,-1,33$ points; sorrow: $-5,44 \%,-3,25$ points).

\section{REAL-LIFE BEHAVIOR}

Only four of 348 participants ${ }^{5}$ decided to share the petition to the President. Two of them (seven days before) watched a film with additional arousal of sorrow, one - a film with additional inspirations of pride, and one - an emotionally neutral film. Moreover, two of them were assigned to write a short informative text, and other two - to write a short persuasive text. Therefore, collected data cannot be used to verify how different emotions and presence of commitment may influence political behavior of recipients of the remembrance policy. However, it legitimizes a statement that inspiring just low commitment is not sufficient to change recipients' behavior, and that it cannot be recognized as an

516 participants did not share with us their contact details, so they could not be informed about the petition. 
effective strategy of political mobilization of citizens. In the follow-up study we will introduce high commitment condition, where participants will be asked to not only write a short persuasive text, but also to present it in the front of other participants - as a result, we want to verify if high commitment may be used to manipulate citizens' behavior thanks to remembrance narratives.

Nevertheless, the experimental study delivered some information about a relationship between narrating past experiences and recipients' behavior. We noticed that a result of the attitudes questionnaire may be used to predict respondent's actions. In the case of participants who expressed their positive or highly positive attitude towards the government's remembrance policy, the expected behavior was six times more likely than in the case of all participants. Therefore, we assume that further studies (and replication of this study in different conditions) will confirm that citizens who support a government as the leading narrator of the national history are more likely to engage themselves in promotion of narratives and commemorative actions.

\section{DISCUSSION OF RESULTS}

Presented results of the experimental study cannot be recognized as a final validation of theoretical hypotheses on relationships between arousal of emotions and commitment, and the effectiveness of remembrance narratives. However, they lead us to few interesting and valuable observations. Firstly, presence of emotions do not reduce educational role of story-telling. Secondly, use of positive emotions increases a narrative's influence on recipients' attitudes. Thirdly, presence of a committing act intensifies impact of emotions, and it can be used to reduce negative outcomes of arousal of negative emotions. Fourthly, results of the study confirmed that the combination of positive emotions and low commitment is the most effective strategy of story-telling. Fifthly, we noticed that the influence of remembrance narratives is not limited to citizens who are interested in history and politics and a story can also inspire less involved recipients.

We hope that the realized project will be a beginning of long-term investigations of the government's remembrance policy, its influence and effectiveness. It offered an insight into using the history as a political asset, but it rather inspired new questions than finally answered already existing ones. It is clear that it delivered valuable data, which can be used to explain how the remembrance policy works, but it also showed how many different variables should be considered 
in further studies: from types of narratives, through various levels of commitment, to the role of recurrence of an act of story-telling. We believe that this project was a very first stage of empirical verification of predictions in laboratory conditions.

\section{REFERENCES:}

Barsade S.G., Gibson D.E. (2007). Why Does Affect Matter in Organizations?"Academy of Management Perspectives" 21.

Baumeister R.F., Bratslavsky E., Finkenauer C., Vohs K.D. (2001). Bad is Stronger Than Good. "Review of General Psychology" 5.

Boyatzis R.E., Smith M.L., Beveridge A. (2013). Coaching with Compassion: Inspiring Health, Well-Being, and Development in Organizations. "Journal of Applied Behavioral Science" 49.

Boyatzis R.E., Rochford K., Jack A.I. (2014). Antagonistic Neural Networks Underlying Differentiated Leadership Roles. "Frontiers in Human Neuroscience" 8.

Böhner G., Wänke M. (2004). Postawy i zmiana postaw. Gdańsk: Gdańskie Wydawnictwa Psychologiczne.

Burke P.J., Stets J.E. (2009). Identity Theory. Oxford-New York: Oxford University Press.

Cialdini R. (2003). Influence. Science and Practice. Boston: Allyn and Bacon.

Crawford M. (2006). Commemoration: Where Remembering and Forgetting Meets. [in:] Time and Memory. J.A. Parker, M. Crawford, P. Harrison (eds). Leiden-Boston: Brill.

Fredrickson B.L., Losada M.F. (2005). Positive Affect and the Complex Dynamics of Human Flourishing. "American Psychologist" 60.

Grosswald Curran V. (2003). The Politics of Memory / Errinerungspolitik and the Use Propriety of Law in the Process of Memory Construction. "Law and Critique" 14.

Gillis J.R. (1994). Memory and Identity: The History of a Relationship. [in:] Commemorations: The Politics of National Identity. J.R. Gillis (ed.). Princeton: Princeton University Press.

Hoskins G. (2007). The Politics of Memory and the World Trade Center Memorial Site. "Journal of Social Philosophy" 38.

Kattago S. (2001). Ambiguous Memory. The Nazi Past and German National Identity. Westport: Praeger.

Kiesler C.A. (1971). The Psychology of Commitment. Experiments Linking Behavior to Belief. New York: Academic Press.

Kiesler C.A. (1977). Sequential Events in Commitment. "Journal of Personality" 45.

Kiesler C.A., Munson P.A. (1975). Attitudes and Opinions. "Annual Review of Psychology" 26.

Koczanowicz L. (1997). Memory of Politics and Politics of Memory. Reflections on the 
Construction of the Past in Post-Totalitarian Poland. "Studies in East European Thought" 49.

Kossowska M. (2003). Różnice indywidualne w potrzebie poznawczego domknięcia. "Przegląd Psychologiczny" 46.

Kossowska M., Bukowski M., Czarnek G. (2014). Two Routes to Closure: Time Pressure and Goal Activation Effects on Executive Control. "Polish Psychological Bulletin" 45.

Labanyi J. (2008). The Politics of Memory in Contemporary Spain. "Journal of Spanish Cultural Studies" 9.

Landau M.J., Sullivan D., Greenberg J. (2009). Evidence That Self-Relevant Motives and Metaphoric Framing Interact to Influence Political and Social Attitudes. "Psychological Science" 20.

Levenson R.W., Ekman P., Friesen W.V. (1990). Voluntary Facial Action Generates Emotion-Specific Autonomic Nervous System Activity. "Psychophysiology" 27.

Maruszewski T. (2001). Psychologia poznania. Sposoby rozumienia siebie i świata. Gdańsk: Gdańskie Wydawnictwo Psychologiczne.

Misztal B.A. (2010). Collective Memory in a Global Age. Learning How and What to Remember. "Current Sociology" 58.

Porges S.W. (2001). The Polyvagal Theory: Phylogenetic Substrates of a Social Nervous System. "International Journal of Psychophysiology" 42.

Rao V.S., Monk A. (1999). The Effects of Individual Differences and Anonymity on Commitment to Decisions: Preliminary Evidence. "The Journal of Social Psychology" 139.

Schwartz L., Jennings K., Petrillo J., Kidd R.F. (1980). Role of Commitment in the Decision to Stop a Theft. "The Journal of Social Psychology" 110.

Schwarz N., Clore G.C. (1983). Mood, Misattribution, and Judgements of Well-Being: Informative and Directive Functions of Affective States. "Journal of Personality and Social Psychology" 45.

Singer J.A., Conway M.A. (2008). Should We Forget Forgetting?"Memory Studies" 1.

Smith R. (2003). Stories of Peoplehood: The Politics and Morality of Political Membership. New York: Cambridge University Press.

Turner J.H. (2007). Human Emotions. A Sociological Theory. London-New York: Routledge.

Uldricks T.J. (2009). War, Politics and Memory. Russian Historians Reevaluate the Origins of World War II. "History \& Memory" 21.

Westen D. (2008). The Political Brain. The Role of Emotion in Deciding the Fate of the Nation. New York: Public Affairs. 